\title{
Palmar rheumatoid nodulosis associated with local pressure
}

\author{
Eldad Ben-Chetrit, Claes Enk, Alan Rubinow
}

\begin{abstract}
Rheumatoid nodulosis is a term used to describe adult patients with rheumatoid arthritis with little or no clinical joint inflammation who have numerous subcutaneous nodules indistinguishable from those of patients with active rheumatoid arthritis. This paper reports the case of a woman with quiescent rheumatoid arthritis who developed palmar nodulosis three weeks after the strenuous activity of painting her apartment. This case illustrates the direct association between the appearance of nodulosis and physical pressure despite inactive disease.
\end{abstract}

(Ann Rheum Dis 1992; 51: 1005-1006)

Rheumatoid nodules are common extra-articular manifestations of rheumatoid arthritis. Their incidence is $20-25 \%$ in adults with a greater percentage $(90 \%)$ in severely ill patients who are positive for rheumatoid factor. ${ }^{1}$ Although generally associated with more severe articular and systemic disease massive nodules may occur in patients with little or no detectable synovitis. ${ }^{2}$ When the nodules are numerous and not associated with active articular or systemic disease, the term rheumatoid nodulosis is used. ${ }^{3}$ The nodules are most commonly found on extensor surfaces and on areas subject to pressure such as the elbow, occiput, or sacrum.

This paper reports the case of a woman with quiescent rheumatoid arthritis who developed palmar nodulosis three weeks after the strenuous activity of painting her apartment.

Rheumatology Unit,

Department of Medicine,

Hebrew University-

Hadassah Hospital,

Jerusalem, Israel

E Ben-Chetrit

A Rubinow

Department of

Dermatology,

Hebrew University-

Hadassah Hospital,

Jerusalem, Israel

C Enk

Correspondence to:

Dr E Ben-Chetrit,

Department of Medicine,

Hadassah University

Hospital, POB 12000,

Jerusalem 91120 , Israel.

Accepted for publication

8 November 1991

\section{Case report}

A 41 year old woman who had had seropositive rheumatoid arthritis for eight years presented to our outpatient clinic with multiple palmar nodules. She had been treated beneficially with gold injections and non-steroidal anti-inflammatory drugs for five years and for the last three years was asymptomatic while receiving $200 \mathrm{mg} /$ day hydroxychloroquine (Plaquenil). She reported that three weeks previously no nodule was apparent on her palms and she felt well. Physical examination showed a thin woman with mild deformities of her hands and multiple non-tender nodules located to the flexor surfaces of her palms (fig 1). No sign of active arthritis was noted.

Laboratory tests gave the following results: haemoglobin of $120 \mathrm{~g} / \mathrm{l}$; white blood cell count $7 \cdot 5 \times 10^{9} / 1$; and thrombocytes $250 \times 10^{9} / 1$. The erythrocyte sedimentation rate was $30 \mathrm{~mm} /$ hour

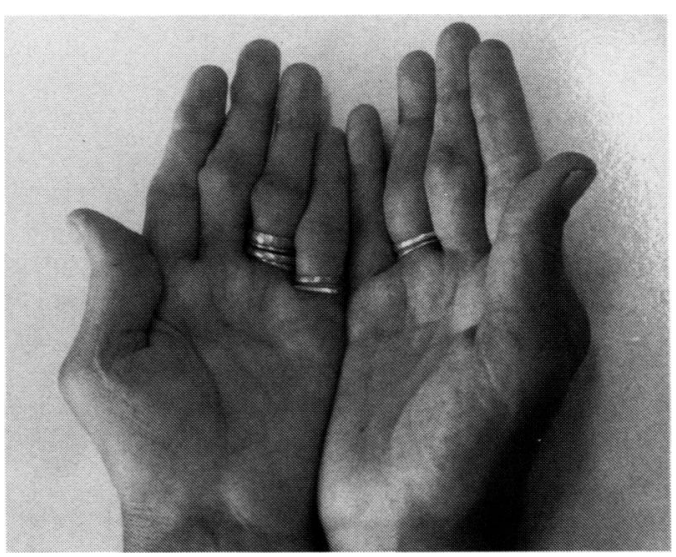

Figure 1 Rheumatoid nodulosis on both palms of the patient.

(Westergren). Rheumatoid factor (latex fixation test) was positive in a titre of $1 / 32$. A fluorescent antinuclear factor test was positive $(+2 /+4)$. Liver and kidney functions were normal. A biopsy sample from a palmar nodule was characteristic of a rheumatoid nodule (fig 2).

The patient reported that during preparations for Passover three weeks previously she had painted the walls and doors of her apartment. The sites of the nodule formation conformed to areas of pressure related to use of the paint brush or roller.

\section{Discussion}

Rheumatoid nodules are granulomatous lesions which are still a key finding in patients with rheumatoid arthritis. Generally such nodules are associated with more severe articular and systemic disease and high titres of rheumatoid factor. In 1949 Bywaters described a particular variant of rheumatoid arthritis characterised by transient digital pad nodules and palmar contractures resembling palindromic rheumatism. ${ }^{2}$ In 1975 the term rheumatoid nodulosis was used for adult patients with little or no clinical joint inflammation but with numerous subcutaneous nodules with a histopathology indistinguishable from seropositive rheumatoid arthritis. ${ }^{3}$ The criteria for the diagnosis of rheumatoid nodulosis are not clear. Some workers have described subchondral cysts as necessary for the diagnosis, ${ }^{45}$ whereas others have reported patients with rheumatoid nodulosis without radiological lesions. ${ }^{67}$ Couret et $a^{8}{ }^{8}$ suggested that the diagnosis of rheumatoid nodulosis should be based on the following four criteria: (a) no or mild systemic mani- 

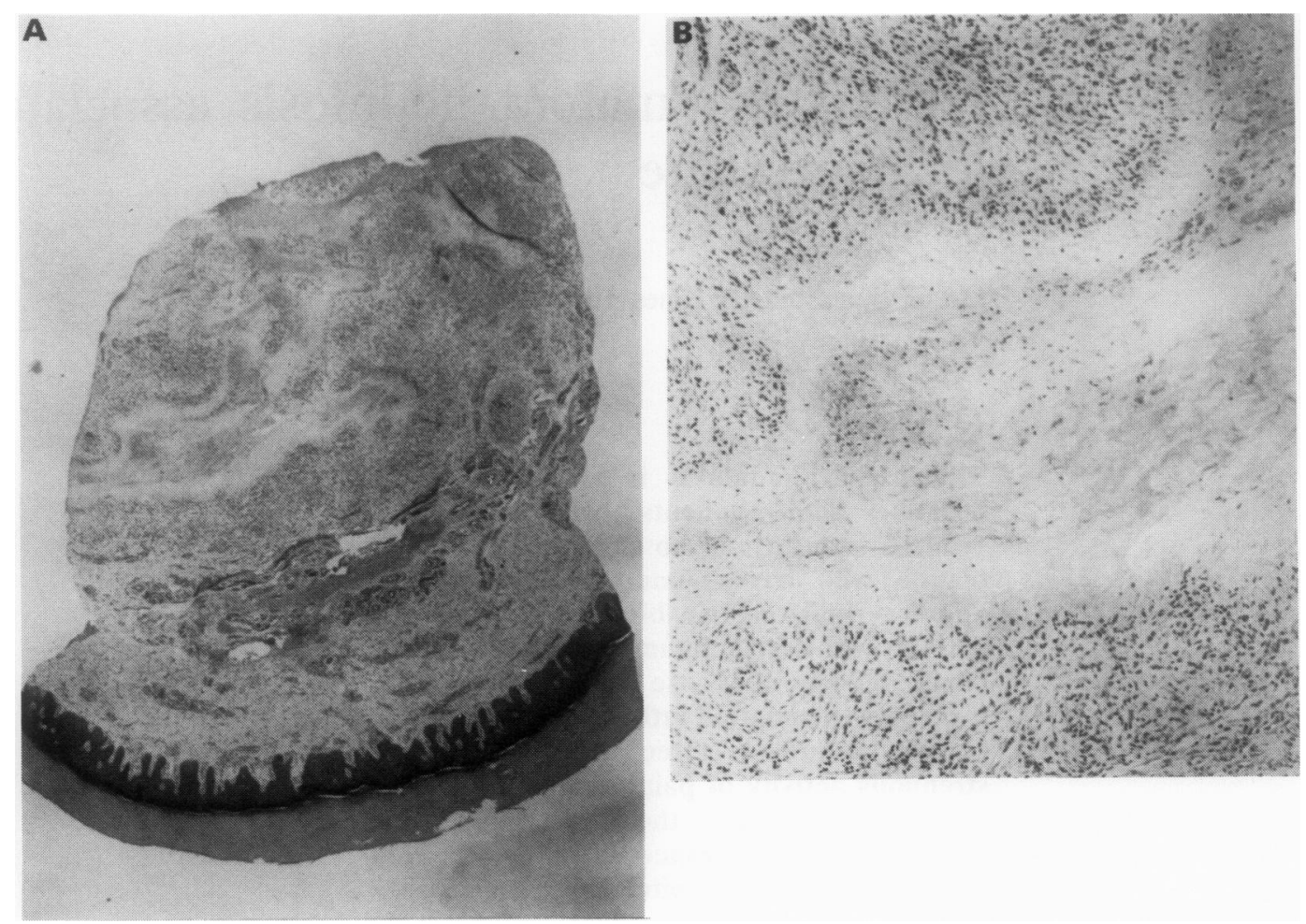

Figure 2 (A) Biopsy sample from palmar nodule showing typical necrotic focus surrounded by pallisades of proliferating histiocytes. (B) Higher magnification of the nodule.

festations of rheumatoid arthritis; (b) benign clinical course; $(c)$ recurrent joint symptoms with minimal clinically or radiologically detectable disease; and (d) multiple rheumatoid nodules identified by taking biopsy samples.

Typically the nodules appear on the extensor surfaces of the forearm below the elbow and are presumably associated with mild repetitive traumatic pressure. Subcutaneous nodules may be confused clinically with joint xanthomas, granuloma annulare, and tophi or multicentric histiocytosis. ${ }^{4}$

The appearance of nodules in this patient deserves comment. First, the number of nodules and their appearance during a quiescent period suggest the diagnosis of rheumatoid nodulosis. Second, the temporal relation between the strenuous effort of decorating with repetitive pressure over the palms of her hands and the appearance of the nodules support the part played by trauma in the pathogenesis of these lesions.

Each year many Israeli patients suffer trauma related to the traditional intensive preparations for Passover or spring cleaning. Patients with rheumatoid arthritis, regardless of disease activity, should avoid the kind of activities that require strenuous repetitive movement or local pressure on body surfaces.

1 Schumacher H R, Gall E P, eds. Rheumatoid arthritis. Philadelphia: Lippincott, 1988.

2 Bywaters E G. A variant of rheumatoid arthritis characterized by recurrent digital pad nodules and palmar fasciitis, by recurrent digital pad nodules and palmar fasciitis, closely resembling

3 Ginsburg M H, Genant H U, Yu T F, McCarty D J. Rheumatoid nodulosis: an unusual variant of rheumatoid disease. Arthritis Rheum 1975; 18: 49.

4 Wisnieski J J, Askarii Ad. Rheumatoid nodulosis. Arch Intern Med 1981; 141: 515-9.

5 Morales-Piga A, Elena-Ibanez A, Zea-Mendoza A C Rocamora-Ripoll A, Beltran-Gutierez J. Rheumatoid nodulosis: report of a case with evidence of intraosseous rheumatoid granuloma. Arthritis Rheum 1986; 29: 1278-83.

6 Schreiber S, Schumacher H R, Cherian P V. Palindromic rheumatism with rheumatoid nodules: a case report with ultrastructural studies. Ann Rheum Dis 1986; 45: 78-81.

7 Brown M M, Hadler N M, Sams W M, Wilson J, Snyderman R. Rheumatoid nodulosis, sporadic and familial diseases. R. Rheumatoid nodulosis, sp

8 Couret M, Combe B, Chicong V T, Leroux J L, Blotman F, Sany J. Rheumatoid nodulosis: report of two new cases and discussion of diagnostic criteria. $\mathcal{J}$ Rheumatol 1988; 15: 1427-30. 